\title{
CASO 21-2015:Femenina de 30 años, con Lupus Eritema- toso Sistémico y Mielitis Transversa Longitudinalmente Extendida.
}

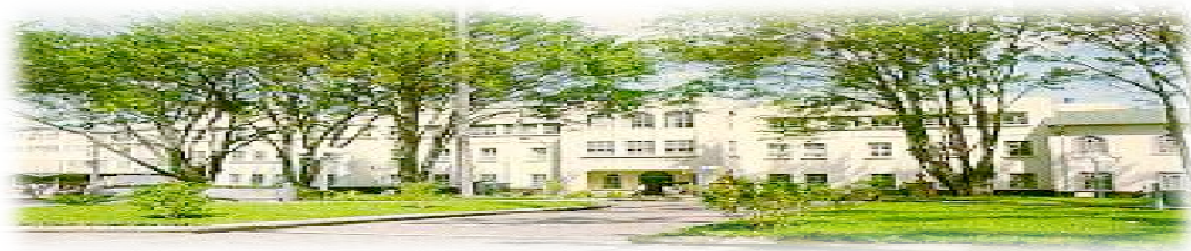

Hospital San Juan de Dios, San José, Costa Rica. Fundado en 1845
ISSN

Recibido:

$18 / 06 / 2015$

Aceptado:

$2 / 09 / 2015$

Marvin Sánchez Benavides ${ }^{1}$ Johanna Vásquez Cespedes ${ }^{2}$

${ }^{1}$ Medico Asistente Especialista en Reumatología, Hospital Dr. Rafael Ángel Calderón Guardia. CCSS.

Correo electrónico: marsbcr@gmail.com

${ }^{2}$ Medico Residente de neurología, Hospital Dr. Rafael Ángel Calderón Guardia. CCSS. Correo electrónico: jmvc84@hotmail.com

\section{RESUMEN}

Paciente femenina de 30 años, con antecedente de depresión crónica y diagnostico reciente de Lupus Eritematoso Sistémico (LES), consulta por cuadro de dos días de evolución caracterizado por debilidad en miembros inferiores, que posteriormente asocia parestesias, paraplejia flácida, retención urinaria e incontinencia fecal. Al examen físico se documenta VI par derecho con nistagmo horizontal, arreflexia en miembros inferiores, globo vesical y nivel sensitivo T6. Ante la sospecha de mielitis transversa se inicia inmunosupresión con esteroides intravenosos más ciclofosfamida mensual y aféresis, tras lo cual se evidencia una paulatina mejoría clínica. Se realizó una resonancia magnética del cordón espinal que evidenció lesiones difusas hiperintensas en la secuencia T2 con compromiso longi- tudinal desde el tercio distal espinal hasta el cono medular compatible con Mielitis Transversa Longitudinalmente Extendida (LETM). Se egresa de la Unidad de Cuidados Intensivos con mejoría clínica y se continúa manejo con ciclofosfamida mensual. Actualmente persiste con discreta hipoestesia en silla de montar y deambula sin dificultad con bastón. Se reporta un caso de LETM en LES, a la fecha se han reportado menos de 30 casos en la literatura mundial.

\section{PALABRAS CLAVE}

Lupus Eritematoso Sistémico, mielitis longitudinal, mielopatía. 


\section{ABSTRACT}

A 30 years-old woman with chronic depression and Systemic Lupus Erythematosus since one month ago, who presented a 2 days history of progressive lower limbs weakness and afterward developed paresthesias,flaccid paraplejia, vesical atonia with urinary retention and constipation. Physical examination disclosed right sixth cranial nerve palsy with horizontal diplopia and nystagmus, absent deep tendon reflexes in the lower extremities, sphincter dysfuntion and sensory level at T6. Transverse myelitis was suspected and patient was treated with intravenous pulses steroids, monthly pulses cyclophosphamide and apheresis with symptoms improve. Spinal cord MRI was performed and showed hyperintense diffuse lesions in the T2 weighted images with longitudinal involvement from the spinal distal third to connus medullaris compatible with longitudinally extensive transverse myelitis (LETM). Patient was discharged from ICU with clinical improvement and monthly cyclophosphamide was continued. At present she persists with saddle hypoesthesia and uses a walking cane without difficulty.

We report one case of acute LETM, just a few cases has been reported in world literature.

\section{KEY WORDS}

Systemic Lupus Erythematosus, longitudinal myelitis, myelopathy.

\section{CASO CLÍNICO}

Se presenta una paciente femenina de 30 años, con antecedente de un cuadro depresivo crónico en tratamiento con Amitriptilina 10mg HS, Lamotrigina $100 \mathrm{mg}$ c/día, Clonazepam $1 \mathrm{mg} \mathrm{c} / 8 \mathrm{~h}$, y diagnostico reciente de Lupus Eritematoso Sistémico (LES) en base a manifestaciones articulares, cutáneas, anticardiolipina y anticoagulante lúpico positivos, Anti $\mathrm{ADN} \mathrm{db}>200$, hipocomplementemia, serositis y anticuerpos antinucleares positivos, en tratamiento con Prednisona $10 \mathrm{mg}$ c/día, Metotrexate $10 \mathrm{mg}$ IM semanal, Acido Fólico $1 \mathrm{mg}$ c/día, Hidroxicloroquina $310 \mathrm{mg}$ c/día, Calcio $600 \mathrm{mg}$ c/día y Vitamina D $0,25 \mathrm{mcg}$ c/día.
La paciente consulta al segundo nivel de atención por cuadro de un día de evolución caracterizado por debilidad en miembros inferiores (MsIs) y vómitos incoercibles manejados en forma sintomática, con lo que mejora el cuadro clínico y se egresa ese mismo día. Posteriormente, a los 2 días la debilidad evoluciona a paraplejía flácida y parestesias en miembros inferiores con dolor ardoroso y alodinia, retención urinaria, incontinencia fecal y diplopía; por lo que decide consultar al Servicio de Emergencias del Hospital Dr. Rafael Ángel Calderón Guardia.

El examen físico inicial documenta una paciente consciente, eupneica, sin ulceras orales, artritis, serositis, datos de fotosensibilidad, lenguaje normal, Lhermitt positivo, VI par craneal derecho con nistagmo horizontal cuando dirige la mirada hacia la derecha, diplopía a la mirada lateral bilateral, mirada vertical normal, fuerza muscular $0 / 5$ en miembros inferiores y normal en miembros superiores, hipotonía en miembros inferiores, arreflexia rotuliana y aquilea, nivel sensitivo a nivel de T6 y globo vesical que requiere sonda Foley fija.

Los estudios de laboratorio documentaron hipocomplementemia, proteinuria, elevación de reactantes de fase aguda, anemia normo-normo y linfopenia(cuadro I).

Cuadro I: valores iniciales de laboratorio.

\begin{tabular}{|c|c|}
\hline Variable & Valor \\
\hline $\begin{array}{l}\text { Hemoglobina } \\
\text { Hematocrito }\end{array}$ & $\begin{array}{l}9.1 \mathrm{~g} / \mathrm{dl} \\
30 \%\end{array}$ \\
\hline Plaquetas & $205000 \mathrm{uds} / \mathrm{ml}$ \\
\hline Leucocitos & $5470 \mathrm{uds} / \mathrm{ml}$ \\
\hline Linfocitos & $629 \mathrm{uds} / \mathrm{ml}$ \\
\hline VES & $100 \mathrm{~mm} / \mathrm{h}$ \\
\hline PCR & $0.6 \mathrm{mg} / \mathrm{dl}$ \\
\hline UN & $18 \mathrm{mg} / \mathrm{dl}$ \\
\hline Creatinina & $1.00 \mathrm{mg} / \mathrm{dl}$ \\
\hline Fracción C3 & $69 \mathrm{mg} / \mathrm{dl}$ \\
\hline Fracción C4 & $4 \mathrm{mg} / \mathrm{dl}$ \\
\hline Anti ADN db & $>200 \mathrm{AAU} / \mathrm{ml}$ \\
\hline Orina de 24 horas & $500 \mathrm{mg} / 24 \mathrm{~h}$ \\
\hline
\end{tabular}

Fuente: revisión del expediente clínico.

Los exámenes inmunológicos para Síndrome Antifosfolípido demostraron anticardiolipinas, 
antibeta2glicoproteina $1 \mathrm{y}$ anticoagulante lúpico negativos.

Se realizó además una velocidad de conducción nerviosa que documentó polineuropatía axonal asimétrica sensitiva-motora de miembros inferiores, líquido cefalorraquídeo con pleocitosis de predominio segmentados, hipoglucorraquia, e hiperproteinorraquia.

La tomografía axial computada de encéfalo y tórax se reportaron normales.

Ante la sospecha clínica de mielitis transversa se inicia terapia inmunosupresora con metilprednisolona $1 \mathrm{~g}$ c/día por tres días y ciclofosfamida 900mg IV sin mejoría de los síntomas clínicos. Dado que la evolución no es satisfactoria se comenta caso a la Unidad de Cuidados Intensivos (UCI) para inicio de aféresis.

Paciente se ingresa a UCI donde se inicia terapia con cinco sesiones de aféresis con albumina al $20 \%$ cada 48 horas.

Posterior a la segunda sesión de aféresis se nota una discreta mejoría neurológica, leve movilidad distal en ambos MsIs, resolución del nistagmo, recuperación de la sensibilidad distal. Se inicia fisioterapia con mejoría paulatina de la fuerza distal.

Se realiza resonancia magnética nuclear $(\mathrm{RMN})$ que demuestra hiperintensidad a nivel del tercio distal hasta cono medular sugestivo de mielitis transversa longitudinalmente extendida (LETM por sus siglas en ingles) (figura 1).

Paciente se egresa de UCI sin diplopía ni parálisis del VI par craneal, fuerza muscular $2 / 5$ en MsIs, sin alodinia, con persistencia de anestesia en silla de montar, incontinencia fecal y globo vesical con necesidad de sonda Foley.

En salón se continua con sesiones de fisiatría y se traslada al Centro Nacional de Rehabilitación (CENARE) con mejoría clínica franca. Actualmente la paciente se encuentra en control en el servicio de Reumatología, deambula sin ayuda con bastón, no presenta incontinencia fecal o necesidad de sonda Foley, pero persiste con discreta hipoestesia en silla de montar, con normalización de los laboratorios en su última cita control (cuadro2), manejado con azatioprina y plaquinol sin esteroides orales.

Figura 1: RMN de columna espinal con compromiso desde tercio distal hasta cono medular

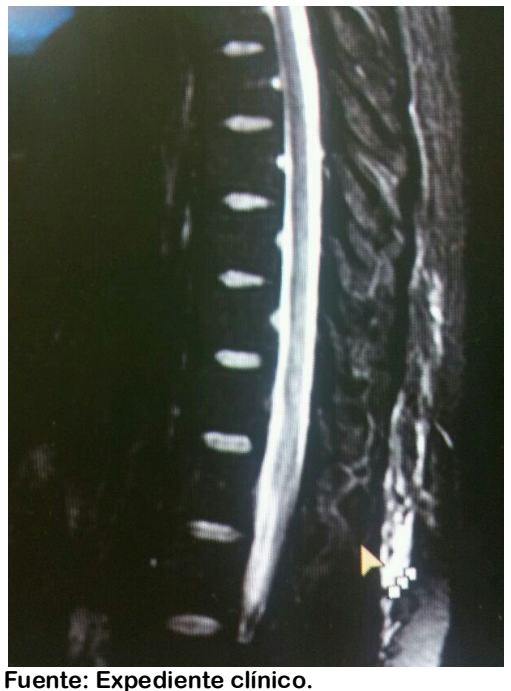

Cuadro II: Valores de laboratorio en consulta externa

\begin{tabular}{|l|l|}
\hline Variable & Valor \\
\hline Hemoglobina & $12.3 \mathrm{~g} / \mathrm{dl}$ \\
Hematocrito & $38 \%$ \\
\hline Plaquetas & $344000 \mathrm{uds} / \mathrm{ml}$ \\
\hline Leucocitos & $5380 \mathrm{uds} / \mathrm{ml}$ \\
Linfocitos & $1641 \mathrm{uds} / \mathrm{ml}$ \\
\hline UN & $15 \mathrm{mg} / \mathrm{dl}$ \\
Creatinina & $0.60 \mathrm{mg} / \mathrm{dl}$ \\
\hline Fracción C3 & $164 \mathrm{mg} / \mathrm{dl}$ \\
Fracción C4 & $24 \mathrm{mg} / \mathrm{dl}$ \\
Anti ADN db & $16 \mathrm{AAU} / \mathrm{ml}$ \\
\hline VES & $24 \mathrm{~mm} / \mathrm{h}$ \\
PCR & No hay reactivo. \\
\hline
\end{tabular}

UN: nitrógeno ureico, C3: Fracción C3 del complemento, C4: Fracción C4 del complemento, VES: velocidad de eritrosedimentación, PCR: proteína $C$ reactiva. Anti ADNdb: anticuerpos antidoble cadena.

Fuente: revisión del expediente clínico.

\section{DISCUSIÓN Y ANÁLISIS DEL CASO}

La mielitis transversa se define como una emergencia médica, con una incidencia anual de 1-4 casos/millón, con distribución bimodal entre los 10-19 años y los 30-39 años. Desde el punto de vista etiológico se ha asociado a procesos infecciosos virales o bacterianos, enfermedades autoinmunes como Lupus Eritematoso Sistémico (LES), Síndrome Antifosfolípido (SAF) y Síndrome de Sjögren, infarto espinal y esclerosis múltiple entre otros ${ }^{(1)}$ 
La mielitis transversa longuitudinalmente extendidad (LETM)se define como una mielopatía que afecta más de 4 segmentos espinales ${ }^{(1,2)}$. Consisteen una rara, pero severa complicación del LES, con un grado variable de secuelas hasta en $80 \%$ de los casos ${ }^{(1)}$. Una cohorte de 22 pacientes demostró que $1 / 3$ de los pacientes no presentará secuelas, $1 / 3$ presentará un grado moderado de incapacidad y $1 / 3$ presentará secuelas severas permanentes ${ }^{(1)}$.

Se ha observado peor pronóstico neurológico en pacientes lúpicos con LETM que aquellos con mielitis transversa con menos de 4 segmentos afectados, pacientes con cuadro clínico severo en las primeras 12 horas de evolución y aquellos con manifestaciones severas iniciales ${ }^{1}$, incluyendo incontinencia de esfínteres, paraparesia o tetraparesia $^{(1,3)}$.

El primer caso reportado en la literatura de LETM en pacientes con LES fue descrito en 1999 en una paciente con compromiso desde C3 hasta T2 y desde T7 hasta el cono medular ${ }^{(4)}$.

Se desconoce la prevalencia de LETM en pacientes lúpicos, a la fecha se han reportado menos de 30 pacientes. En general se calcula que la mielitis transversa afecta entre $1-2 \%$ de pacientes con LES y $0.4 \%$ de pacientes con Síndrome Antifosfolípido ${ }^{(1)}$.

Clásicamente LETM se asocia a Neuromielitis Óptica(NMO) ${ }^{(5)}$, no obstante puede observarse en otras patologías inflamatorias como Sarcoidosis, Enfermedad de Behcet, Esclerosis Múltiple, Síndrome de Sjögren, infecciones como tuberculosis, así como trauma medular y procesos neoplásicos ${ }^{(1,2,6,7)}$. Se ha reportado LETM posterior a vacuna contra el virus Influenza A H1N1 ${ }^{(8)}$.

Las manifestaciones clínicas de LETM son variadas. Una cohorte de 22 pacientes demostró el déficit sensitivo en $91 \%$, déficit motor en $86 \%$ y disfunción de esfinteres en $83 \%$ de los casos, como los más frecuentemente reportados. Otras manifestaciones incluyendo fiebre, cefalea, arreflexia y tetraparesia se han descrito en menor proporción ${ }^{(1)}$.

El mecanismo patogénico inicial se desconoce a la fecha. Un punto fundamental lo constituye el rol de los anticuerpos antifosfolípidos, al momento no está claro si el evento desencadenante inicial es de carácter inflamatorio, trombótico o una combinación de ambos ${ }^{1}$. Una cohorte de 22 pacientes lúpicos con LETM presentó serología positiva para anticuerpos antifosfolípidos en 50\% de los casos ${ }^{(1)}$. Basado en hallazgos histopatoló- gicos se considera la trombosis de las arterias espinales relacionado con anticuerpos antifosfolípidos como el mecanismo patogénico de la mielopatía en LES, especialmente por su predominio a nivel torácico. No obstante el rol del fenómeno trombótico en LETM no ha sido claramente dilucidado, especialmente por la extensión de las lesiones ${ }^{(1)}$.

Otros mecanismos patogénicos propuestos incluyen fenómenos vasculiticos y degeneración de sustancia blanca ${ }^{(9)}$.

El estudio diagnostico de elección ante la sospecha clínica de LETM es la RMN, clásicamente se observa hiperintensidad medular en la secuencia T2 que abarca más de 4 segmentos medulares ${ }^{(5)}$. Además permite establecer diagnósticos diferenciales y descartar otras causas como hematomas o tumores intramedulares ${ }^{(3)}$.

Otros estudios de laboratorio y gabinete incluyen análisis del liquido cefalorraquídeo que evidencia incremento en el conteo de leucocitos a expensas de polimorfonucleares o linfocitos en menor proporción, elevación en los niveles de anticuerpos anti ADN doble cadena y disminución en los niveles de complemento sérico ${ }^{(1)}$.

A la fecha no existe consenso en relación al tratamiento de $\operatorname{LETM}^{(1)}$.

El tratamiento agresivo y precoz se asocia a mejor recuperación neurológica ${ }^{(3)}$. La piedra angular actual consiste en altas dosis de esteroides (metilprednisolona 0.5g- $1 \mathrm{~g}$ por 3-5 días) ${ }^{(1,9)}$. Dicho esquema se ha prescrito en $86 \%$ de los pacientes reportados ${ }^{(9)}$. Otras terapias incluyen inmunosupresores como ciclofosfamida, azatioprina, rituximab y gammaglobulina intravenosa en menor proporción de casos ${ }^{(1,9)}$. El inmunosupresor mas asociado aesteroides es ciclofosfamida en $45 \%$ de los casos ${ }^{(9)}$.El rol de la aféresis no es claro, aunque algunos reportes de casos evidencian un rol beneficioso en pacientes refractarios o críticamente enfermos ${ }^{(1)}$.

Existe escaza y controversial evidencia en relación a la anticoagulación en pacientes con LETM y anticuerpos antifosfolípidos positivos ${ }^{(1,3)}$. Considerando el posible rol de dichos anticuerpos, se ha utilizado la antiagregación y la anticoagulación cada uno en $18 \%$ de los casos reportados, con adecuada respuesta solo en $14 \%{ }^{(9)}$. En general se recomienda la anticoagulación en pacientes con LETM y fenómenos trombóticos documentados especialmente en el contexto de Síndrome Antifosfolipido ${ }^{(3)}$. 


\section{CONCLUSIONES}

Se reporta un caso de LETM en una paciente con LES dé recién diagnostico con adecuada respuesta a la terapia agresiva y precoz con altas dosis de esteroides,inmunosupresión y aféresis. A la fecha se han reportado en la literatura menos de 30 casos de LETM en pacientes lúpicos.

\section{BIBLIOGRAFÍA}

1.Espinosa G Mendizábal A Mínguez S RamoTello et al.. Transverse mielitis affecting more than 4 spinal segments associated with systemic lupus erythematosus: clinical, immunological, and radiological characteristics of 22 patients. Semin Arthritis Rheum 2010;39:246-256.

2.Trebs C Raab P Voss V et al. Longitudinal extensive transverse myelitis it $\ddot{s}$ not all neuromyelitisoptica. Nature Reviews Neurology 7, 688-698 (december 2011).

3. White C Leonard B Patel A Longitudinally extensive transverse myelitis: a catastrophic presentation of a flare-up of systemic lupus erythematosus. CMAJ 2012 Feb 21; 184(3): e197E200.

4.Deodhar AA Hochenedel T Bennett RM. Longitudinal involvement of the spinal cord in a patient with lupus related transverse myelitis. $\mathrm{J}$ Rheumatol 1999;26:446-449.

5.Kitley JL Leite MI George SJ Palace JA. The differential diagnosis of longitudinally extensive transverse myelitis. MultScler 2012 Mar; 18(3):271-85.

6.Dolhun R Sriram S. Neurosarcoidosis presenting as longitudinally extensive transverse myelitis. J ClinNeurosci. 2009 April; 16(4): 595-7.

7.Graham D Mc Carthy A Kavanagh E O"Rourke K Lynch T. Longitudinally extensive transverse myelitis in neuro-Behcet disease. Neurology 04/2013; 80(18): e189-90.

8.Akkad W Salem B Freeman JW Huntington MK. Longitudinally Extensive Transverse Myelitis Following Vaccination With Nasal Attenuated Novel Influenza A(H1N1) Vaccine. Arch Neurol 2010; 67(8): 1018-1020.

9.Huang L Chung C Chen B Chi N Hu C. Systemic Lupus Erythematosus Presented as Extensive Longitudinal Myelitis. ActaNeurol Taiwan $2013 ; 22: 67-71$.

\section{CONFLICTO DE INTERÉS Y/O AGRADE- CIMIENTOS}

Los autores declaran que no existió ningún conflicto de interés en el presente reporte. 